\title{
Phthaloylchitosan-Based Gel Polymer Electrolytes for Efficient Dye-Sensitized Solar Cells
}

\author{
S. N. F. Yusuf, ${ }^{1}$ M. F. Aziz, ${ }^{1}$ H. C. Hassan, ${ }^{1}$ T. M. W. J. Bandara, ${ }^{2,3}$ \\ B.-E. Mellander, ${ }^{2}$ M. A. Careem, ${ }^{1}$ and A. K. Arof ${ }^{1}$ \\ ${ }^{1}$ Department of Physics, Centre for Ionics University of Malaya, Faculty of Science, University of Malaya, \\ 50603 Kuala Lumpur, Malaysia \\ ${ }^{2}$ Department of Applied Physics, Chalmers University of Technology, 41296 Gothenburg, Sweden \\ ${ }^{3}$ Department of Physical Sciences, Rajarata University of Sri Lanka, 50300 Mihintale, Sri Lanka
}

Correspondence should be addressed to S. N. F. Yusuf; farhanayusuf@ymail.com

Received 24 April 2014; Accepted 6 June 2014; Published 23 June 2014

Academic Editor: Yu Xin Zhang

Copyright (C) 2014 S. N. F. Yusuf et al. This is an open access article distributed under the Creative Commons Attribution License, which permits unrestricted use, distribution, and reproduction in any medium, provided the original work is properly cited.

\begin{abstract}
Phthaloylchitosan-based gel polymer electrolytes were prepared with tetrapropylammonium iodide, $\operatorname{Pr}_{4} \mathrm{NI}$, as the salt and optimized for conductivity. The electrolyte with the composition of $15.7 \mathrm{wt} . \%$ phthaloylchitosan, 31.7 wt.\% ethylene carbonate (EC), 3.17 wt.\% propylene carbonate (PC), $19.0 \mathrm{wt}$ \% of $\mathrm{Pr}_{4} \mathrm{NI}$, and $1.9 \mathrm{wt}$ \% iodine exhibits the highest room temperature ionic conductivity of $5.27 \times 10^{-3} \mathrm{~S} \mathrm{~cm}^{-1}$. The dye-sensitized solar cell (DSSC) fabricated with this electrolyte exhibits an efficiency of $3.5 \%$ with $J_{\mathrm{SC}}$ of $7.38 \mathrm{~mA} \mathrm{~cm}^{-2}, V_{\mathrm{OC}}$ of $0.72 \mathrm{~V}$, and fill factor of 0.66 . When various amounts of lithium iodide (LiI) were added to the optimized gel electrolyte, the overall conductivity is observed to decrease. However, the efficiency of the DSSC increases to a maximum value of $3.71 \%$ when salt ratio of $\mathrm{Pr}_{4} \mathrm{NI}$ : LiI is $2: 1$. This cell has $J_{\mathrm{SC}}, V_{\mathrm{OC}}$ and fill factor of $7.25 \mathrm{~mA} \mathrm{~cm}^{-2}, 0.77 \mathrm{~V}$ and 0.67 , respectively.
\end{abstract}

\section{Introduction}

A solar cell is a device that directly converts light energy into electrical energy through the photovoltaic process. The solar cells currently produced are generally divided into several types according to their material composition and operating mechanism, such as photoelectrochemical solar cells and thin film junction devices. Photoelectrochemical solar cells have become attractive devices since Gratzel and O' Regan first reported the prototype dye-sensitized solar cell (DSSC) using wide band gap $\mathrm{TiO}_{2}$ semiconductor in 1991 [1]. The DSSC has gained a great deal of attention due to its relatively high energy conversion efficiency and low production cost [2]. DSSCs are also semitransparent and can be produced in various colours, making it possible for them to be applied in building integrated photovoltaic (BIPV) applications [3]. A typical DSSC consists of a nanocrystalline semiconductor coated photoactive electrode, an iodide based liquid electrolyte, and a counter electrode (normally platinum or carbon-based coating on a conducting glass substrate). When the DSSC is irradiated with light, photoexcited electrons of the dye are transferred to the conduction band of $\mathrm{TiO}_{2}$, and the oxidized dye cations are regenerated by the $\mathrm{I}^{-}$in the electrolyte. The $\mathrm{I}_{3}{ }^{-}$formed in this process is reduced at the counter electrode, thus completing the cycle and generating the photocurrent [4]. $\mathrm{I}^{-} / \mathrm{I}_{3}{ }^{-}$redox mediator shuttles between the two electrodes.

In the determination of high efficiency and long time stability of the DSSCs, electrolytes play an important role [5]. A gel polymer electrolyte has been used in this work in order to replace liquid electrolytes that may cause some practical limitations of physical and chemical stability at higher temperatures $[5,6]$. The conductivity of gel type electrolytes is usually high compared to that of solid polymer electrolytes and it can be improved to be almost comparable to that of the conventional electrolyte solutions in case of high solution fraction [7]. Since the solvent is entrapped in the polymer network structure in gel electrolytes, leakage problems can 
be avoided. The solvents entrapped in the polymer matrix not only improve the conductivity of electrolytes but also improve the contacts between interfaces of the electrolyte and the dye covered nanocrystalline $\mathrm{TiO}_{2}$ surface and electrolyte-counter electrode leading to improved efficiency of DSSCs $[5,7]$.

Many host polymers have been used to prepare electrolytes for use in DSSCs [8-11]. In this work, chitosan has been chosen as the host polymer for the electrolyte since this polysaccharide is nontoxic and biocompatible. Chitosan is also being explored intensively for applications in pharmaceutical, cosmetics, biomedical, biotechnological, agricultural, food, and nonfood industries [12-15]. Chitosan is the deacetylated form of the chitin polysaccharide and contains the $\beta$-(1-4) linked 2-amino-2-deoxy-D-glucopyranose repeating structure $[16,17]$. Chitosan is generally insoluble under normal conditions due to the presence of $\beta-1,4^{\prime}$ glycosidic linkages that gives chitosan its structural rigidity and crystalline structure besides promoting the formation of intramolecular hydrogen bonds. This limits its usage and further investigation for the biological activities and development has been restricted [18]. Since chitosan and its derivatives are favourable for many applications, chitosan should be effectively modified to fully explore its ability. The chemical modification of chitosan can provide functional groups as primary amine as well as secondary hydroxyl groups in its monomers [12].

In order to improve the solubility of chitosan in general organic solvents, $N$-phthaloylation is found to be one of the convenient methods. Kurita et al. have applied $N$ phthaloylchitosan as an organosoluble key intermediate for a series of controlled modification reactions [19-21]. Chemical introduction of some functional groups of hydrophobic nature will result in disruption of the formation of specific hydrogen bond interactions between its amino and hydroxyl groups with the solvents [22]. N-Phthaloylchitosan exhibits high affinity for organic solvents, namely, dimethylsulfoxide (DMSO), dimethylacetamide (DMAc), dimethylformamide (DMF), and pyridine [23]. In this work, we aim at developing a best performing DSSC using a $N$-phthaloylchitosan-based gel polymer electrolyte. Therefore, gel polymer electrolytes were prepared with various amounts of tetrapropylammonium iodide, $\mathrm{Pr}_{4} \mathrm{NI}$, as the salt and investigated in order to find the best composition for high conductivity. $\mathrm{Pr}_{4} \mathrm{NI}$ has been chosen as the primary iodide salt for the electrolyte as it has been shown to produce good efficiencies in DSSCs by enhancing the iodide conductivity in the electrolyte [24, 25]. The performances of the electrolytes were tested in DSSCs based on mesoporous $\mathrm{TiO}_{2}$ sensitized with N719 dye as the sensitizer. The performance of the best DSSC was improved further with the addition of a second iodide salt, LiI.

\section{Experimental}

2.1. Phthaloylation of Chitosan. The synthesis procedure used in this work is similar to that reported by Nishimura et al. [22]. Chitosan (Aldrich) and phthalic anhydride (Aldrich) were refluxed between $100^{\circ} \mathrm{C}$ and $120^{\circ} \mathrm{C}$ under nitrogen atmosphere for $6 \mathrm{~h}$ in dimethylformamide (DMF) purchased
TABLE 1: $\mathrm{Pr}_{4}$ NI content of different electrolyte samples.

\begin{tabular}{lcc}
\hline Samples & $\mathrm{PhCh} / \mathrm{g}$ & $\mathrm{Pr}_{4} \mathrm{NI} / \mathrm{g}$ \\
\hline 1 & 0.1 & 0.02 \\
2 & 0.1 & 0.04 \\
3 & 0.1 & 0.06 \\
4 & 0.1 & 0.08 \\
5 & 0.1 & 0.10 \\
6 & 0.1 & 0.12 \\
7 & 0.1 & 0.14 \\
8 & 0.1 & 0.16 \\
\hline
\end{tabular}

TABLE 2: Composition of the salts in binary salt electrolytes.

\begin{tabular}{lcc}
\hline Samples & $\mathrm{Pr}_{4} \mathrm{NI} / \mathrm{g}$ & $\mathrm{LiI} / \mathrm{g}$ \\
\hline $\mathrm{A}$ & 0.12 & 0.00 \\
$\mathrm{~B}$ & 0.10 & 0.02 \\
$\mathrm{C}$ & 0.08 & 0.04 \\
$\mathrm{D}$ & 0.06 & 0.06 \\
$\mathrm{E}$ & 0.04 & 0.08 \\
\hline
\end{tabular}

from $\mathrm{R} \& \mathrm{M}$ Chemicals. The temperature was then reduced to $60^{\circ} \mathrm{C}$, and the mixture was left overnight. The product of reaction between chitosan and phthalic anhydride dissolved in DMF is a yellowish solution. This solution was poured into ice water to precipitate the product, $N$-phthaloylchitosan. The precipitate was collected and washed with distilled ethanol (from J. T. Baker) in a soxhlet extractor for $8 \mathrm{~h}$. The final product was dried in vacuum at $60^{\circ} \mathrm{C}$ for about $6 \mathrm{~h}$.

2.2. Preparation of Gel Polymer Electrolyte (GPE). Fixed amounts of ethylene carbonate $(0.2 \mathrm{~g})$ and propylene carbonate $(0.2 \mathrm{~g})$ from Aldrich were stirred well in a closed glass container with the relevant weights of $\mathrm{Pr}_{4} \mathrm{NI}$ (see Table 1). $0.1 \mathrm{~g}$ of phthaloylchitosan was then added to each salt solution. The mixture was heated to $150^{\circ} \mathrm{C}$ and stirred until the mixture becomes a homogeneous gel. Then heater was stopped and the solution was allowed to cool down to room temperature. Iodine (10 wt.\% of salt) was then added to the gel polymer electrolyte and stirred until the solution becomes homogeneous. The impedance of the resulting gel polymer electrolyte was then measured.

To the most conducting gel polymer electrolyte (Sample 6), lithium iodide, LiI, was added in such a way that the total weight of the iodide salts remains the same $(0.12 \mathrm{~g})$ in all the electrolytes. The salt compositions used in the electrolytes are shown in Table 2.

2.3. Device Assembly. Fluorine tin oxide (FTO) glasses (from Solaronix SA), which were used as the substrates, were rinsed with distilled water and ethanol before use. For preparing $\mathrm{TiO}_{2}$ layer on the substrate, $\mathrm{TiO}_{2}$ colloidal suspension was prepared by grinding $0.5 \mathrm{~g}$ powder of $\mathrm{TiO}_{2}$ with $2 \mathrm{~mL}$ of $\mathrm{HNO}_{3}, 0.1 \mathrm{~g}$ of carbowax, and few drops of surfactant octylphenol ethylene oxide condensate (Triton X-100) in an agate mortar. The $\mathrm{TiO}_{2}$ colloidal suspension was spread on 


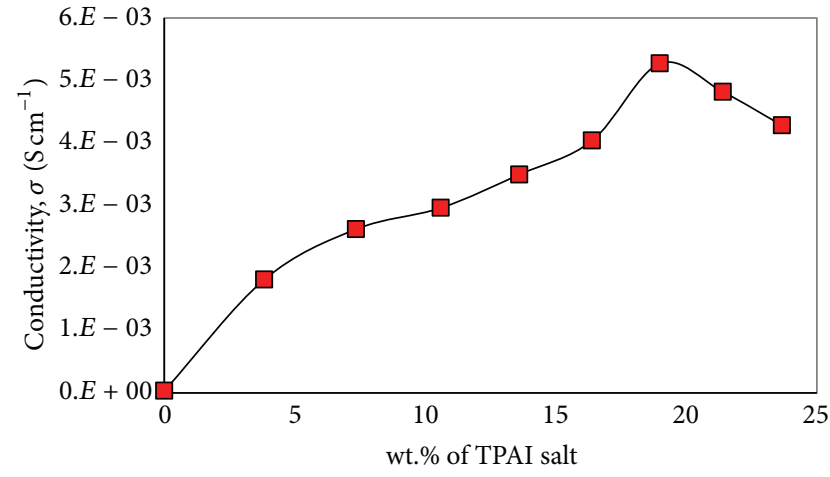

FIGURE 1: Effect of $\operatorname{Pr}_{4} \mathrm{NI}$ concentration on the conductivity at $25^{\circ} \mathrm{C}$.

the clean (FTO) glass by applying the doctor blade technique. The $\mathrm{TiO}_{2}$ electrode was sintered in a furnace at $450^{\circ} \mathrm{C}$ for 45 minutes. The $\mathrm{TiO}_{2}$ electrode was cooled down to about $60^{\circ} \mathrm{C}$ and then dipped in a warm ethanol solution of Ruthenium dye (N719) for 24 hours for dye adsorption.

The photovoltaic performance of DSSCs was investigated using a LOT-Oriel solar simulator $\left(1.5 \mathrm{AM}, 1000 \mathrm{~W} \mathrm{~m}^{-2}\right)$ and a computer controlled eDAQ Potentiostat. From the $J$ $V$ (current density-cell potential) characteristic curves, the short-circuit current $\left(J_{\mathrm{SC}}\right)$ and open circuit voltage $\left(V_{\mathrm{OC}}\right)$ were obtained and the fill factor (FF) and energy conversion efficiency $(\eta)$ were calculated from the following equations:

$$
\begin{gathered}
\mathrm{FF}=\frac{J_{\text {max }} \times V_{\text {max }}}{J_{\mathrm{SC}} \times V_{\mathrm{OC}}}, \\
\eta=\frac{P_{\text {out }}}{P_{\text {in }}} \times 100=\frac{J_{\mathrm{SC}} \times V_{\mathrm{OC}} \times \mathrm{FF}}{P_{\text {in }}} \times 100,
\end{gathered}
$$

where $J_{\max }$ is the current density at maximum power output, $V_{\max }$ is the voltage at maximum power output, and $P_{\text {in }}$ is the power of the incident light.

\section{Results and Discussion}

Figure 1 shows the variation of conductivity at room temperature for the phthaloylchitosan-based gel polymer electrolytes with various $\mathrm{Pr}_{4} \mathrm{NI}$ salt compositions. The conductivity of the electrolyte with the lowest $\operatorname{Pr}_{4} \mathrm{NI}$ concentration, 3.8 wt.\%, is $1.81 \times 10^{-3} \mathrm{~S} \mathrm{~cm}^{-1}$ at $25^{\circ} \mathrm{C}$. With increasing amount of $\mathrm{Pr}_{4} \mathrm{NI}$ salt up to $19.0 \mathrm{wt}$ \% in gel polymer host, the ionic conductivity increases until a maximum conductivity of $5.27 \times 10^{-3} \mathrm{~S} \mathrm{~cm}^{-1}$ at $25^{\circ} \mathrm{C}$. On increasing the $\mathrm{Pr}_{4} \mathrm{NI}$ concentration further, the conductivity is observed to decrease.

This behavior of the conductivity can be attributed to the change in the amount of mobile ions in the gel electrolytes [26]. The increase in number of mobile ions due to the increased salt dissociation with the increasing amount of salt in the electrolyte can result in the conductivity increase. The $\mathrm{Pr}_{4} \mathrm{NI}$ salt molecules are expected to dissociate into $\operatorname{Pr}_{4} \mathrm{~N}^{+}$ cations and $\mathrm{I}^{-}$anions in the GPE. As the $\operatorname{Pr}_{4} \mathrm{~N}^{+}$cations are bulky they are expected to have sluggish movement or get trapped in the polymer matrix and therefore ionic

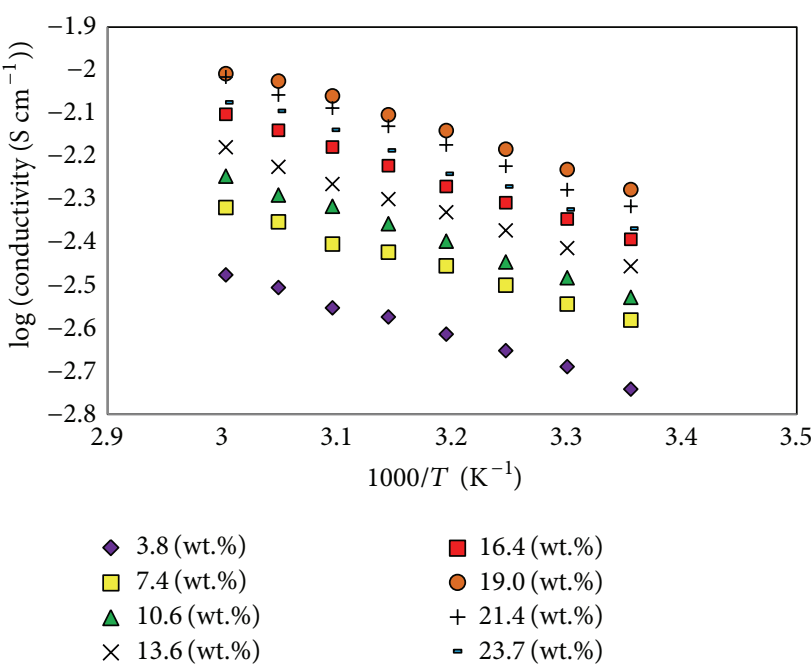

FIgURE 2: Temperature dependence of conductivity for phthaloylchitosan doped with different wt.\% of $\mathrm{Pr}_{4}$ NI salt.

conductivity mainly comes from the $\mathrm{I}^{-}$ions. Initially as the salt concentration increases, since dissociated ions are less, both $\mathrm{I}^{-}$ions and $\mathrm{Pr}_{4} \mathrm{~N}^{+}$ions can be expected to be mobile and contribute to ionic conduction and the conductivity rises sharply. On further increase of salt content, the number of both $\mathrm{Pr}_{4} \mathrm{~N}^{+}$ions and $\mathrm{I}^{-}$ions increases but the mobility of $\mathrm{Pr}_{4} \mathrm{~N}^{+}$ions is hindered due to entanglement in the polymer matrix and $\mathrm{I}^{-}$ions may be main contributor to the conductivity. Therefore, the conductivity increases only slightly with further increase in salt content up to about $16.4 \mathrm{wt} . \%$ of salt. Beyond this concentration of the salt the conductivity again rises sharply due to the increase in iodide ions coming from increased salt dissociation and increased added iodine amount, which is $10 \mathrm{wt} . \%$ of iodide salt, giving the maximum conductivity at $19 \mathrm{wt} . \%$ of salt content. At $21.4 \mathrm{wt} . \%$ and 23.7 wt.\% of $\mathrm{Pr}_{4} \mathrm{NI}$, ion association may have taken place in the system as the conductivity begins to decrease. In addition, conductivity can drop due to blocking effects imposed by the undissociated salt or due to higher ion aggregates present in the electrolyte at high salt concentrations.

The conductivity-temperature relationship of phthaloylchitosan-EC-PC electrolytes with different amounts of $\mathrm{Pr}_{4} \mathrm{NI}$ is exhibited in a plot of $\log \sigma$ versus $1000 / T$ shown in Figure 2. It is observed that the conductivity of each electrolyte increases as the temperature is increased from $25^{\circ} \mathrm{C}$ to $60^{\circ} \mathrm{C}$. The variations of ionic conductivity with temperature for the polymer electrolytes obey Arrhenius law, suggesting that the conductivity is thermally activated. The Arrhenius model employed in describing the temperature dependence of conductivity is as follows:

$$
\log \sigma=\log \sigma_{o}-\frac{0.4342 E_{a}}{k T},
$$

where $\sigma_{o}$ is the preexponential factor, $E_{a}$ is the activation energy of ionic conduction, $k$ is the Boltzmann constant, and $T$ is temperature in Kelvin. 
TABLE 3: Performance parameters of DSSCs with phthaloylchitosan-based electrolytes containing various salt contents.

\begin{tabular}{|c|c|c|c|c|c|c|}
\hline wt. $\%$ of $\mathrm{Pr}_{4} \mathrm{NI}$ & $V_{\max } / \mathrm{V}$ & $J_{\max } / \mathrm{mA} \mathrm{cm}^{-2}$ & $V_{o c} / \mathrm{V}$ & $J_{\mathrm{sc}} / \mathrm{mA} \mathrm{cm}^{-2}$ & FF & $\eta / \%$ \\
\hline 3.8 & 0.10 & 0.78 & 0.19 & 1.59 & 0.26 & 0.07 \\
\hline 7.4 & 0.51 & 3.54 & 0.68 & 3.24 & 0.69 & 1.79 \\
\hline 10.6 & 0.53 & 4.04 & 0.71 & 4.40 & 0.69 & 2.14 \\
\hline 13.6 & 0.52 & 4.44 & 0.71 & 4.84 & 0.67 & 2.32 \\
\hline 16.4 & 0.48 & 6.08 & 0.67 & 6.39 & 0.68 & 2.92 \\
\hline 19.0 & 0.52 & 6.70 & 0.72 & 7.38 & 0.66 & 3.50 \\
\hline 21.4 & 0.50 & 5.20 & 0.70 & 5.84 & 0.64 & 2.61 \\
\hline 23.7 & 0.51 & 4.94 & 0.67 & 5.56 & 0.68 & 2.53 \\
\hline
\end{tabular}

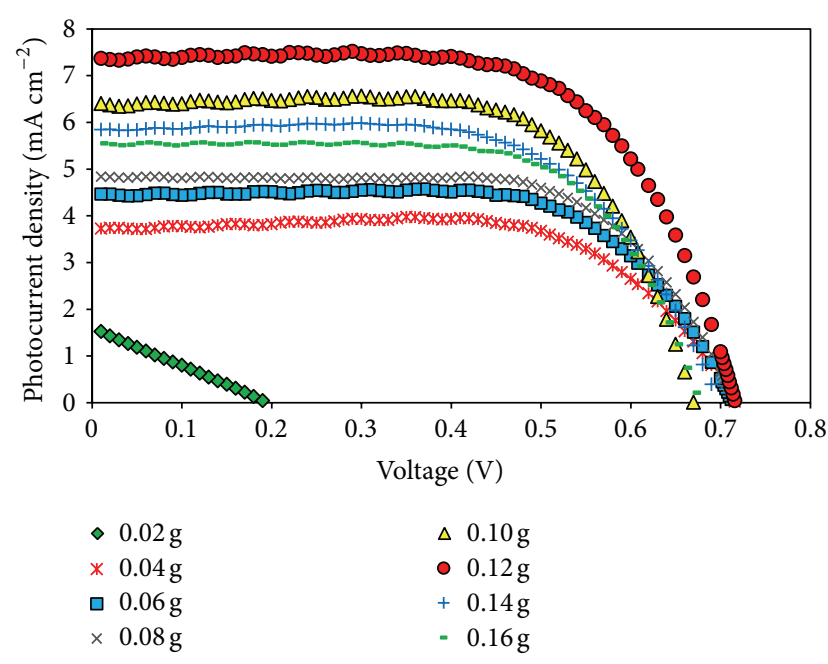

FIGURE 3: Photocurrent density variation with cell potential for dye-sensitized solar cells having phthaloylchitosan-based electrolyte with various $\mathrm{Pr}_{4} \mathrm{NI} / \mathrm{I}_{2}$ contents.

The electrolytes with various amounts of $\operatorname{Pr}_{4} \mathrm{NI}$ were employed in DSSCs sensitized with N719 dye and the photocurrent density versus cell potential $(J-V)$ characteristics were obtained under light irradiation of $100 \mathrm{~mW} \mathrm{~cm}^{-2}$ at room temperature. The $J-V$ curves for the DSSCs are shown in Figure 3. Very poor solar cell performance is shown by the DSSC with the electrolyte containing 3.8 wt.\% of $\operatorname{Pr}_{4}$ NI. This can be due to the poor conductivity and the low density of redox mediators in the electrolyte. However with increasing amount of iodide salt together with increasing iodine content in the electrolyte, better solar cell performance is observed as can be seen from the $J-V$ characteristic curves. The performance parameters for the DSSCs obtained from the $J$ $V$ curves shown in Figure 3 are given in Table 3 . The cell with electrolyte having $19.0 \mathrm{wt}$.\% of $\operatorname{Pr}_{4} \mathrm{NI}$ shows both the highest values of $V_{\mathrm{OC}}=0.72 \mathrm{~V}$ and $J_{\mathrm{SC}}=7.38 \mathrm{~mA} \mathrm{~cm}^{-2}$. Electrolyte with the lowest salt content of $3.8 \mathrm{wt}$.\% shows the lowest values of $V_{\mathrm{OC}}$ and $J_{\mathrm{SC}}$ of about $0.19 \mathrm{~V}$ and $1.59 \mathrm{~mA} \mathrm{~cm}^{-2}$, respectively.

In addition to $V_{\mathrm{OC}}$ and $J_{\mathrm{SC}}$, the performance of the DSSCs is reflected by the parameters of fill factor (FF) and energy conversion efficiency $(\eta)$. The calculated values of FFand $\eta$ are summarized in Table 3 . The DSSC fabricated using

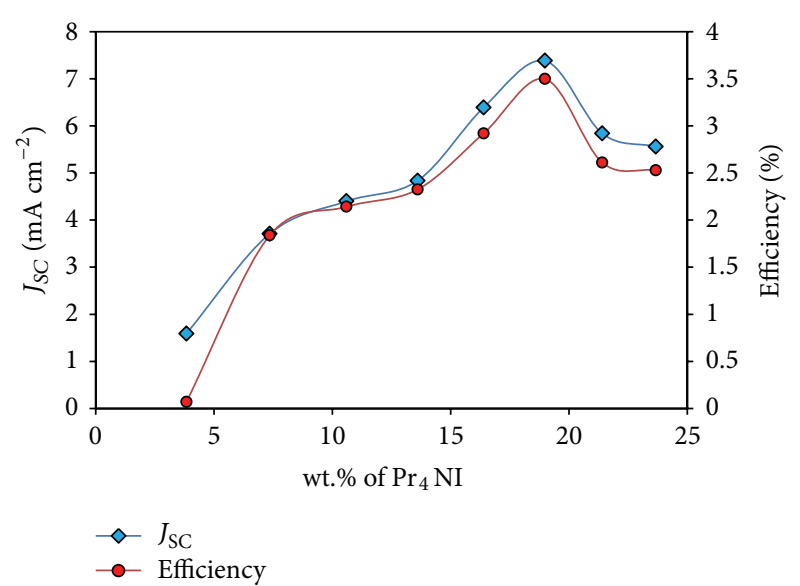

FIGURE 4: Effects of weight percentage of $\mathrm{Pr}_{4} \mathrm{NI}$ salt in the electrolyte on efficiency and short-circuit photocurrent density of DSSCs.

the electrolyte containing 19.0 wt.\% of $\operatorname{Pr}_{4} \mathrm{NI}$ with $\eta$ of 3.50 exhibits fill factor of 0.66 . The highest fill factor was obtained for the DSSC that had the electrolyte containing $19.0 \mathrm{wt} . \%$ of $\mathrm{Pr}_{4}$ NI. This can be attributed to the combined effect of series resistance and shunt resistances as reported in [26]. In a DSSC, low shunt resistance provides a substitute path for light generated current and hence lowers the power output which in turn decreases the fill factor. As series resistance in the DSSC is usually lower when compared to conventional solar cells, improved fill factor is expected.

The relationships between $\operatorname{Pr}_{4} \mathrm{NI}$ content in the electrolyte with efficiency and short-circuit current density are shown in Figure 4. Efficiency of the cells is observed to increase with the $\mathrm{Pr}_{4} \mathrm{NI}$ content until 19.0 wt.\% of $\mathrm{Pr}_{4} \mathrm{NI}$ and further increase of salt decreases the efficiency. Thus the cell with 19.0 wt. $\%$ of $\mathrm{Pr}_{4} \mathrm{NI}$ shows the highest efficiency value of $3.5 \%$, the highest value obtained with the single iodide salt polymer electrolyte system used in this work. The efficiency variation shown in Figure 4 correlates with the conductivity variation shown in Figure 1. Figure 4 also shows that the short-circuit current density of DSSCs increases with increasing concentration of the salt up to $19.0 \mathrm{wt}$. $\%$ of $\mathrm{Pr}_{4} \mathrm{NI}$. It can be seen that the variation of efficiency of the cells is parallel with variation of short-circuit current density as well as the conductivity of the electrolyte with the salt content. The short-circuit current of the cell is governed by the ionic 


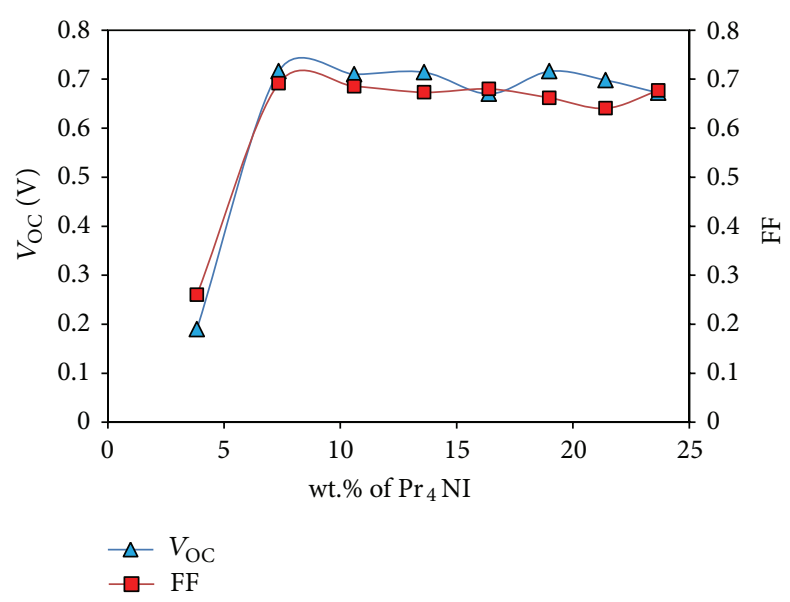

FIGURE 5: Effects of weight percentage of $\mathrm{Pr}_{4} \mathrm{NI}$ salt in the electrolyte on open circuit voltage and fill factor of DSSCs.

conductivity dominated by the transport of $\mathrm{I}^{-} / \mathrm{I}_{3}{ }^{-}$redox couple as exhibited by a comparable PAN based electrolyte system using the same salt and plasticizers [27]. As explained earlier, the iodide ions are the main contributors to the ionic conductivity in the GPE used. Since iodides $\left(\mathrm{I}^{-} / \mathrm{I}_{3}{ }^{-}\right)$play a major role in determining the current in DSSCs, the $J_{\mathrm{SC}}$ should follow the variation of free iodide ions content in the electrolyte and therefore must increase sharply as the salt content increases as more and more iodide ions are expected to be produced due to salt dissociation. According to the results in Figure 1, the number of iodide ions increases up to $19 \mathrm{wt} . \%$ of salt and the number decreases beyond this salt content due to possible ion association taking place. Hence the $J_{\mathrm{SC}}$ is expected to follow this trend. But in Figure 4, as the salt content increases, $J_{\mathrm{SC}}$ increases sharply at the beginning up to $7.4 \mathrm{wt} . \%$ of salt and beyond $13.6 \mathrm{wt} . \%$ up to $19 \mathrm{wt} . \%$ of salt content. The increase becomes less steep for the salt contents between 7.4 and 13.6 wt.\%. It should be noted that the current in the DSSC is not only controlled by the iodide conduction in the electrolyte but also controlled by the electron injection rate from the dye molecules to $\mathrm{TiO}_{2}$ and the recombination rate of injected electrons with the iodide ions in the electrolyte. The injection rate is also affected by the cations as they can stick to the $\mathrm{TiO}_{2}$ surface and shift the Fermi level. The combined effect of all these processes results in the observed variation of $J_{\mathrm{SC}}$ with salt content. Further experiments and analysis are needed to explain the exact correlation between ionic conductivity and the $J_{\mathrm{SC}}$.

To our best knowledge, the $J_{\mathrm{SC}}$ and efficiency values obtained in this study for DSSC containing $19.0 \mathrm{wt} . \%$ of $\mathrm{Pr}_{4} \mathrm{NI}$ are the highest values reported so far for a quasisolid state DSSC having chitosan host polymer based electrolyte system with a single iodide salt.

The dependence of $V_{\mathrm{OC}}$ and FF on the weight percentage of $\operatorname{Pr}_{4} \mathrm{NI}$ salt in the electrolyte is shown in Figure 5. The $V_{\mathrm{OC}}$ and FF show similar variations but different to that shown by $J_{\mathrm{SC}}$ in Figure 4. These results show that the efficiency variation of the DSSCs is determined mainly by the changes in $J_{\mathrm{SC}}$.

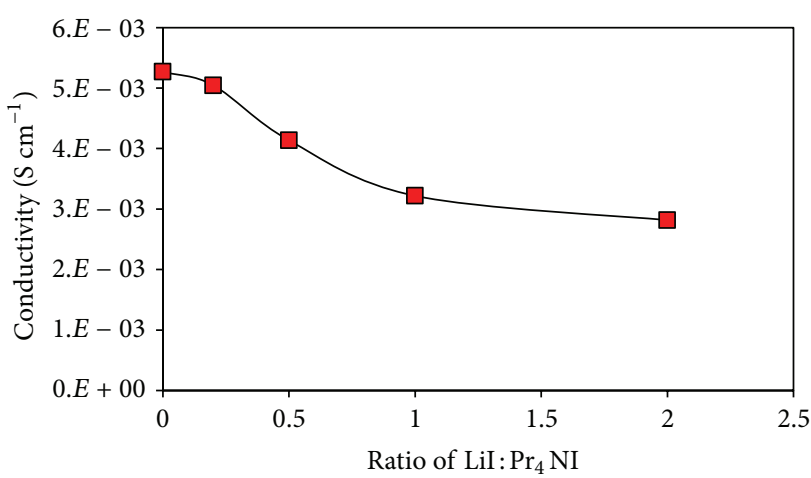

FIgURE 6: Effect of various LiI : $\mathrm{Pr}_{4} \mathrm{NI}$ compositions on the conductivity.

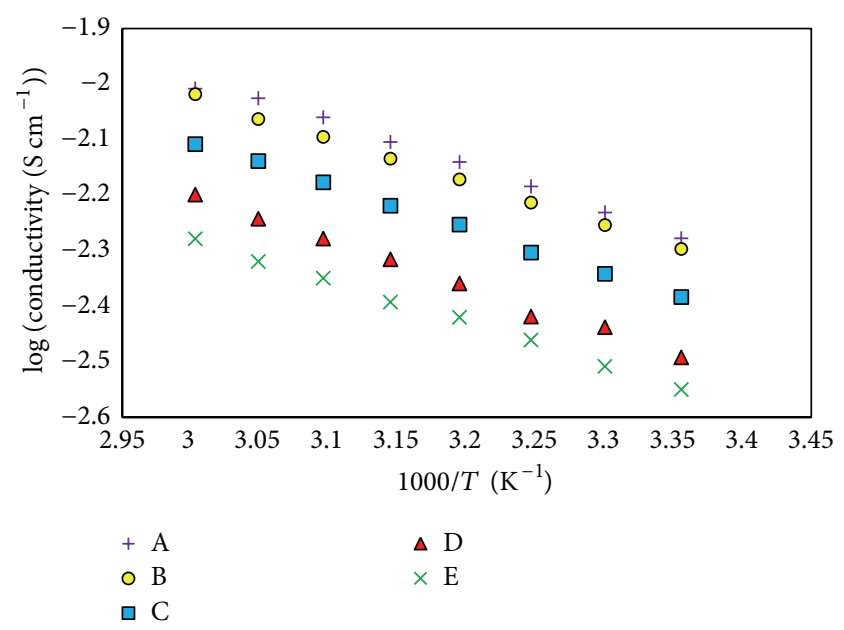

FIGURE 7: Temperature dependence of conductivity for phthaloylchitosan-based electrolyte containing different ratio of $\mathrm{LiI}: \mathrm{Pr}_{4} \mathrm{NI}$ binary salt.

It has been reported that the addition of small cations such as $\mathrm{Li}^{+}, \mathrm{K}^{+}$, and $\mathrm{Mg}^{2+}$ to the gel polymer electrolytes so as to have two mixed cations in the electrolyte improves the solar cell performance [28-30]. In particular these small cations adsorbed onto the $\mathrm{TiO}_{2}$ surface alter the flat band potentials so as to improve the charge injection rates from excited dye molecules to the $\mathrm{TiO}_{2}$ enhancing the photocurrent [31]. Hence in order to improve the photocurrent density of the DSSC various amounts of lithium iodide (LiI) have been added to the most conducting polymer electrolyte, that is, phthaloylchitosan with 19.0 wt.\% of $\operatorname{Pr}_{4}$ NI. Figure 6 shows the room temperature ionic conductivity variation of the gel polymer electrolyte for different mass fractions of the LiI and $\mathrm{Pr}_{4}$ NI. The conductivities of gel polymer electrolytes with various compositions of $\mathrm{LiI}: \mathrm{Pr}_{4} \mathrm{NI}$ at different temperatures are shown in Figure 7. With the addition of LiI conductivity drops are observed at all temperatures in the measured temperature range. This conductivity drop can be attributed to the reduction of polymer flexibility due to inter- and intramolecular cross links by $\mathrm{Li}^{+}$due to its high charge density. The reduction of polymer flexibility can 
TABLE 4: The performance parameters of DSSCs with different gel polymer electrolytes.

\begin{tabular}{|c|c|c|c|c|c|c|}
\hline Electrolyte samples & $V_{\max } / \mathrm{V}$ & $J_{\max } / \mathrm{mA} \mathrm{cm}^{-2}$ & $V_{\mathrm{oc}} / \mathrm{V}$ & $J_{\mathrm{sc}} / \mathrm{mA} \mathrm{cm}^{-2}$ & FF & $\eta / \%$ \\
\hline A & 0.52 & 6.70 & 0.72 & 7.38 & 0.66 & 3.50 \\
\hline B & 0.60 & 6.02 & 0.80 & 6.33 & 0.72 & 3.61 \\
\hline $\mathrm{C}$ & 0.57 & 6.50 & 0.77 & 7.25 & 0.67 & 3.71 \\
\hline $\mathrm{D}$ & 0.61 & 3.35 & 0.75 & 3.64 & 0.75 & 2.04 \\
\hline $\mathrm{E}$ & 0.53 & 3.35 & 0.70 & 3.52 & 0.71 & 1.77 \\
\hline
\end{tabular}

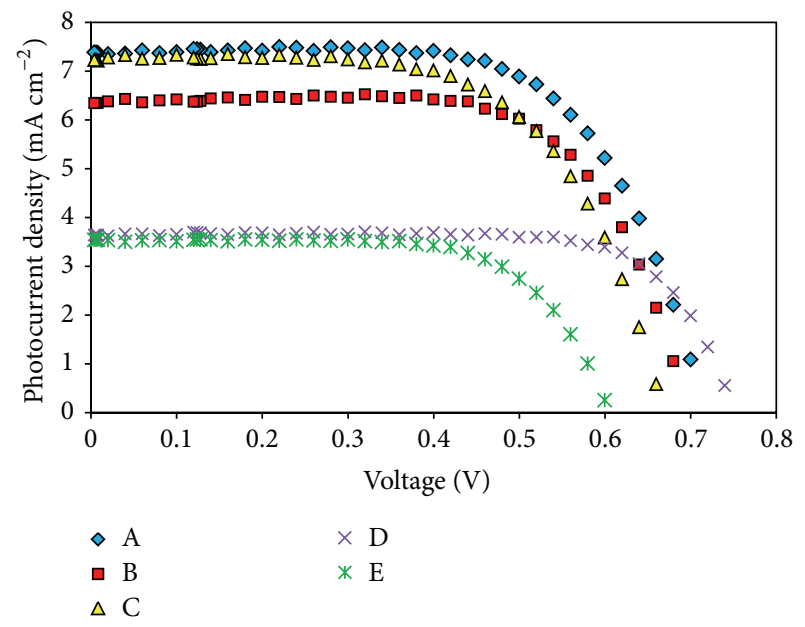

FIGURE 8: Photocurrent-voltage curves of DSSCs with phthaloylchitosan with based electrolyte different ratio of $\mathrm{LiI}$ : $\mathrm{Pr}_{4} \mathrm{NI}$ binary salt.

increase the local viscosity of electrolyte medium hindering mobility of charge carriers. As can be seen from Figure 7, the temperature dependence of conductivity for all electrolytes approximately obeys the Arrhenius relationship as observed in other polymer systems [32].

As expected the incorporation of small amount (less than $0.04 \mathrm{~g}$ ) of LiI into the electrolyte has improved the solar cell performance (see Figure 8) even though these electrolytes have shown a slight decrease in conductivity as shown in Figure 6. The DSSC parameters for the devices having the binary salt system are tabulated in Table 4 . The efficiency reaches a maximum value of $3.71 \%$ for a combination of $0.08 \mathrm{~g} \mathrm{Pr}_{4} \mathrm{NI}$ and $0.04 \mathrm{~g} \mathrm{LiI}$ in the electrolyte. This increase in efficiency can be attributed to the mixed cation effect as observed with many binary salt electrolytes [29, 30]. Mixed cation effect is observed when binary iodide salts having smaller and larger cations are present in the gel electrolyte. The smaller cations get adsorbed to the $\mathrm{TiO}_{2}$ and reduce the Fermi level in such a way to improve the electron injection and, at the same time, the number of iodide ions in the electrolyte increases due to the addition of LiI salt and both these effects increase the current in the DSSC. However, higher amounts of added LiI (more than $0.04 \mathrm{~g}$ ) have reduced the solar cell efficiency due to the ionic conductivity drop as explained above. Variations of efficiency and photocurrent density with different ratio of $\operatorname{Pr}_{4} \mathrm{NI}$ : LiI are shown in Figure 9. The efficiency variation closely follows that of the current density variation.

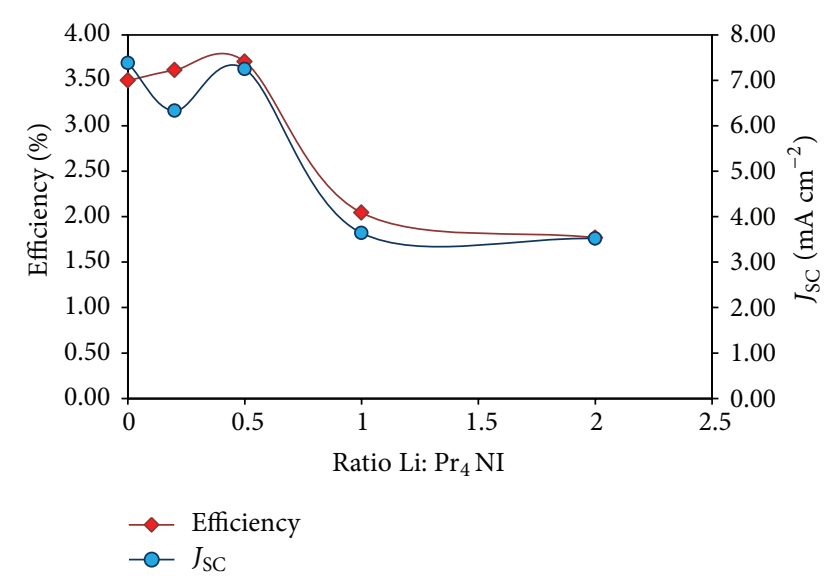

FIgURE 9: Dependence of $J_{\text {SC }}$ and $\eta$ of DSSCs with different gel polymer electrolytes.

\section{Conclusions}

In this work, a gel polymer electrolyte has been successfully prepared using phthaloylchitosan as the polymer host and it has been used to produce high performance in a dyesensitized nanocrystalline solar cell. The most conducting polymer electrolyte containing $19.0 \mathrm{wt}$. $\%$ of $\operatorname{Pr}_{4} \mathrm{NI}$ exhibited the highest efficiency of $3.5 \%$ with $J_{\mathrm{SC}}$ of $7.38 \mathrm{~mA} \mathrm{~cm}^{-2}, V_{\mathrm{OC}}$ of $0.72 \mathrm{~V}$, and FF of 0.66 . The efficiency of the DSSC was further improved to $3.7 \%$ when part of the $\mathrm{Pr}_{4} \mathrm{NI}$ salt in the electrolyte is replaced with $\mathrm{LiI}$ salt $\left(\mathrm{Pr}_{4} \mathrm{NI}: \mathrm{LiI}=2: 1\right)$ with the value of $J_{\mathrm{SC}}, V_{\mathrm{OC}}$ and fill factor of $7.25 \mathrm{~mA} \mathrm{~cm}^{-2}, 0.77 \mathrm{~V}$ and 0.67 , respectively. The presence of the LiI in addition to the $\mathrm{Pr}_{4} \mathrm{NI}$ improves the charge injection rates and increases the iodide contribution to the total conductivity and both factors contribute to the increase in efficiency of the DSSC.

\section{Conflict of Interests}

The authors declare that there is no conflict of interests regarding the publication of this paper.

\section{Acknowledgments}

S. N. F. Yusuf, M. F. Aziz, and H. C. Hassan acknowledge travel supports from Centre for Ionics University of Malaya (CIUM) to carry out part of the experimental work at Chalmers University, Sweden. Research support from The National Research Council Sri Lanka (Grant 11-196), the 
Swedish Research Council, and University of Malaya (Grant no. RP003-13AFR) is gratefully acknowledged.

\section{References}

[1] S. Tan, J. Zhai, B. Xue et al., "Property influence of polyanilines on photovoltaic behaviors of dye-sensitized solar cells," Langmuir, vol. 20, no. 7, pp. 2934-2937, 2004.

[2] T. Horiuchi, H. Miura, K. Sumioka, and S. Uchida, "High efficiency of dye-sensitized solar cells based on metal-free indoline dyes," Journal of the American Chemical Society, vol. 126, no. 39, pp. 12218-12219, 2004.

[3] S. J. Park, K. Yoo, J.-Y. Kim et al., "Water-based thixotropic polymer gel electrolyte for dye-sensitized solar cells," ACS Nano, vol. 7, no. 5, pp. 4050-4056, 2013.

[4] L. Wang, H. Zhang, C. Wang, and T. Ma, "Highly stable gelstate dye-sensitized solar cells based on high soluble polyvinyl acetate," ACS Sustainable Chemistry \& Engineering, vol. 1, no. 1, pp. 205-208, 2012.

[5] J. Shi, S. Peng, J. Pei, Y. Liang, F. Cheng, and J. Chen, "Quasisolid-state dye-sensitized solar cells with polymer gel electrolyte and triphenylamine-based organic dyes," ACS Applied Materials \& Interfaces, vol. 1, no. 4, pp. 944-950, 2009.

[6] Z. Huo, S. Dai, C. Zhang et al., "Low molecular mass organogelator based gel electrolyte with effective charge transport property for long-term stable quasi-solid-state dyesensitized solar cells," The Journal of Physical Chemistry B, vol. 112, no. 41, pp. 12927-12933, 2008.

[7] Y. Saito, H. Kataoka, C. Capiglia, and H. Yamamoto, "Ionic conduction properties of PVDF-HFP type gel polymer electrolytes with lithium imide salts," The Journal of Physical Chemistry B, vol. 104, no. 9, pp. 2189-2192, 2000.

[8] T. M. W. J. Bandara, M. A. K. L. Dissanayake, I. Albinsson, and B.-E. Mellander, "Dye-sensitized, nano-porous $\mathrm{TiO}_{2}$ solar cell with poly(acrylonitrile): $\mathrm{MgI}_{2}$ plasticized electrolyte," Journal of Power Sources, vol. 195, no. 11, pp. 3730-3734, 2010.

[9] G. P. Kalaignan, M.-S. Kang, and Y. S. Kang, "Effects of compositions on properties of $\mathrm{PEO}-\mathrm{KI}-\mathrm{I}_{2}$ salts polymer electrolytes for DSSC," Solid State Ionics, vol. 177, no. 11-12, pp. 1091-1097, 2006.

[10] J. Kang, W. Li, X. Wang et al., "Gel polymer electrolytes based on a novel quaternary ammonium salt for dye-sensitized solar cells," Journal of Applied Electrochemistry, vol. 34, no. 3, pp. 301304, 2004.

[11] S. Y. Bang, K. J. Lee, J. H. Koh, M.-S. Kang, Y. S. Kang, and J. H. Kim, "PEO electrolytes containing dioctyl phthalate (DOP) for dye-sensitized nanocrystalline $\mathrm{TiO}_{2}$ solar cells," Ionics, vol. 14, no. 2, pp. 143-148, 2008.

[12] V. K. Mourya and N. N. Inamdar, "Chitosan-modifications and applications: opportunities galore," Reactive and Functional Polymers, vol. 68, no. 6, pp. 1013-1051, 2008.

[13] M. Y. Abdelaal, T. R. Sobahi, and H. F. Al-Shareef, "Modification of chitosan derivatives of environmental and biological interest: a green chemistry approach," International Journal of Biological Macromolecules, vol. 55, pp. 231-239, 2013.

[14] T. R. A. Sobahi, M. Y. Abdelaal, and M. S. I. Makki, "Chemical modification of chitosan for metal ion removal," Arabian Journal of Chemistry, 2010.

[15] A. Binette and J. Gagnon, "Regioselective silylation of $N$ phthaloylchitosan with TBDMS and TBDPS groups," Biomacromolecules, vol. 8, no. 6, pp. 1812-1815, 2007.
[16] X. Liu, X. Zhi, Y. Liu, B. Wu, Z. Sun, and J. Shen, "Effect of chitosan, $O$-carboxymethyl chitosan, and $N$-[(2-hydroxy-3$\mathrm{N}, \mathrm{N}$-dimethylhexadecyl ammonium) propyl] chitosan chloride on overweight and insulin resistance in a murine diet-induced obesity," Journal of Agricultural and Food Chemistry, vol. 60, no. 13, pp. 3471-3476, 2012.

[17] M. Bodnar, J. F. Hartmann, and J. Borbely, "Synthesis and study of cross-linked chitosan- $N$-poly(ethylene glycol) nanoparticles," Biomacromolecules, vol. 7, no. 11, pp. 3030-3036, 2006.

[18] M. Morimoto, H. Saimoto, H. Usui, Y. Okamoto, S. Minami, and Y. Shigemasa, "Biological activities of carbohydrate-branched chitosan derivatives," Biomacromolecules, vol. 2, no. 4, pp. 11331136, 2001.

[19] K. Kurita, H. Ikeda, Y. Yoshida, M. Shimojoh, and M. Harata, "Chemoselective protection of the amino groups of chitosan by controlled phthaloylation: facile preparation of a precursor useful for chemical modifications," Biomacromolecules, vol. 3, no. 1, pp. 1-4, 2002.

[20] K. Kurita, H. Akao, J. Yang, and M. Shimojoh, "Nonnatural branched polysaccharides: synthesis and properties of chitin and chitosan having disaccharide maltose branches," Biomacromolecules, vol. 4, no. 5, pp. 1264-1268, 2003.

[21] K. Kurita, K. Sugita, N. Kodaira, M. Hirakawa, and J. Yang, "Preparation and evaluation of trimethylsilylated chitin as a versatile precursor for facile chemical modifications," Biomacromolecules, vol. 6, no. 3, pp. 1414-1418, 2005.

[22] S. Nishimura, O. Kohgo, K. Kurita, and H. Kuzuhara, "Chemospecific manipulations of a rigid polysaccharide: syntheses of novel chitosan derivatives with excellent solubility in common organic solvents by regioselective chemical modifications," Macromolecules, vol. 24, no. 17, pp. 4745-4748, 1991.

[23] R. Yoksan, M. Akashi, S. Biramontri, and S. Chirachanchai, "Hydrophobic chain conjugation at hydroxyl group onto $\gamma$-ray irradiated chitosan," Biomacromolecules, vol. 2, no. 3, pp. 10381044, 2001.

[24] T. M. W. J. Bandara, W. J. M. J. S. R. Jayasundara, M. A. K. L. Dissanayake, M. Furlani, I. Albinsson, and B.-E. Mellander, "Effect of cation size on the performance of dye sensitized nanocrystalline $\mathrm{TiO}_{2}$ solar cells based on quasi-solid state PAN electrolytes containing quaternary ammonium iodides," Electrochimica Acta, vol. 109, pp. 609-616, 2013.

[25] O. A. Ileperuma, G. R. A. Kumara, and K. Murakami, "Quasisolid polymer electrolytes based on polyacrylonitrile and plasticizers for indoline dye sensitized solar cells of efficiency 5.3\%," Chemistry Letters, vol. 37, no. 1, pp. 36-37, 2008.

[26] M. Z. A. Yahya and A. K. Arof, "Studies on lithium acetate doped chitosan conducting polymer system," European Polymer Journal, vol. 38, no. 6, pp. 1191-1197, 2002.

[27] M. A. K. L. Dissanayake, L. R. A. K. Bandara, R. S. P. Bokalawala, P. A. R. D. Jayathilaka, O. A. Ileperuma, and S. Somasundaram, "A novel gel polymer electrolyte based on polyacrylonitrile (PAN) and its application in a solar cell," Materials Research Bulletin, vol. 37, no. 5, pp. 867-874, 2002.

[28] Q. Yu, Y. Wang, Z. Yi et al., "High-efficiency dye-sensitized solar cells: the influence of lithium ions on exciton dissociation, charge recombination, and surface states," ACS Nano, vol. 4, no. 10, pp. 6032-6038, 2010.

[29] O. A. Ileperuma, M. A. K. L. Dissanayake, S. Somasunderam, and L. R. A. K. Bandara, "Photoelectrochemical solar cells with polyacrylonitrile-based and polyethylene oxide-based polymer electrolytes," Solar Energy Materials and Solar Cells, vol. 84, no. 1-4, pp. 117-124, 2004. 
[30] M. A. K. L. Dissanayake, C. A. Thotawatthage, G. K. R. Senadeera, T. M. W. J. Bandara, W. J. M. J. S. R. Jayasundera, and B.-E. Mellander, "Efficiency enhancement by mixed cation effect in dye-sensitized solar cells with PAN based gel polymer electrolyte," Journal of Photochemistry and Photobiology A: Chemistry, vol. 246, pp. 29-35, 2012.

[31] A. K. Arof, M. F. Aziz, M. M. Noor et al., "Efficiency enhancement by mixed cation effect in dye-sensitized solar cells with a PVdF based gel polymer electrolyte," International Journal of Hydrogen Energy, vol. 39, no. 6, pp. 2929-2935, 2013.

[32] M. H. Buraidah, L. P. Teo, S. R. Majid, and A. K. Arof, "Ionic conductivity by correlated barrier hopping in $\mathrm{NH}_{4} \mathrm{I}$ doped chitosan solid electrolyte," Physica B: Condensed Matter, vol. 404, no. 8-11, pp. 1373-1379, 2009. 

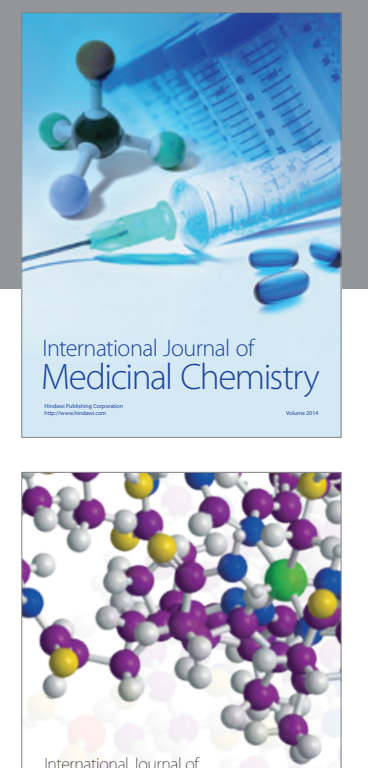

\section{Carbohydrate} Chemistry

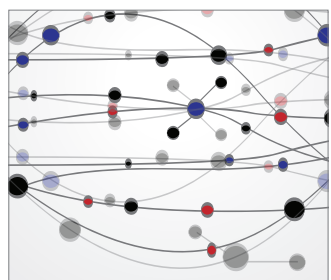

The Scientific World Journal
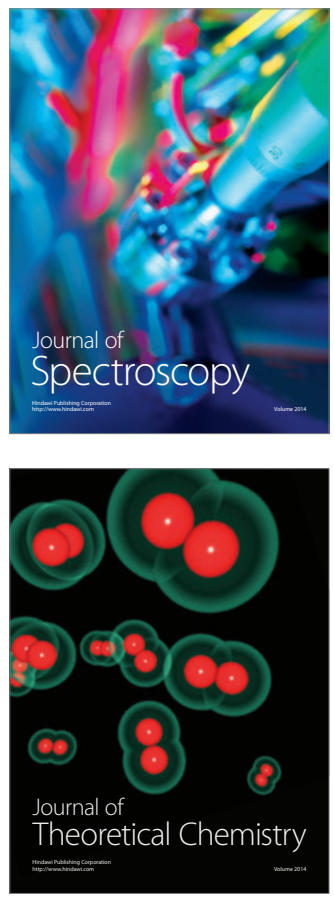
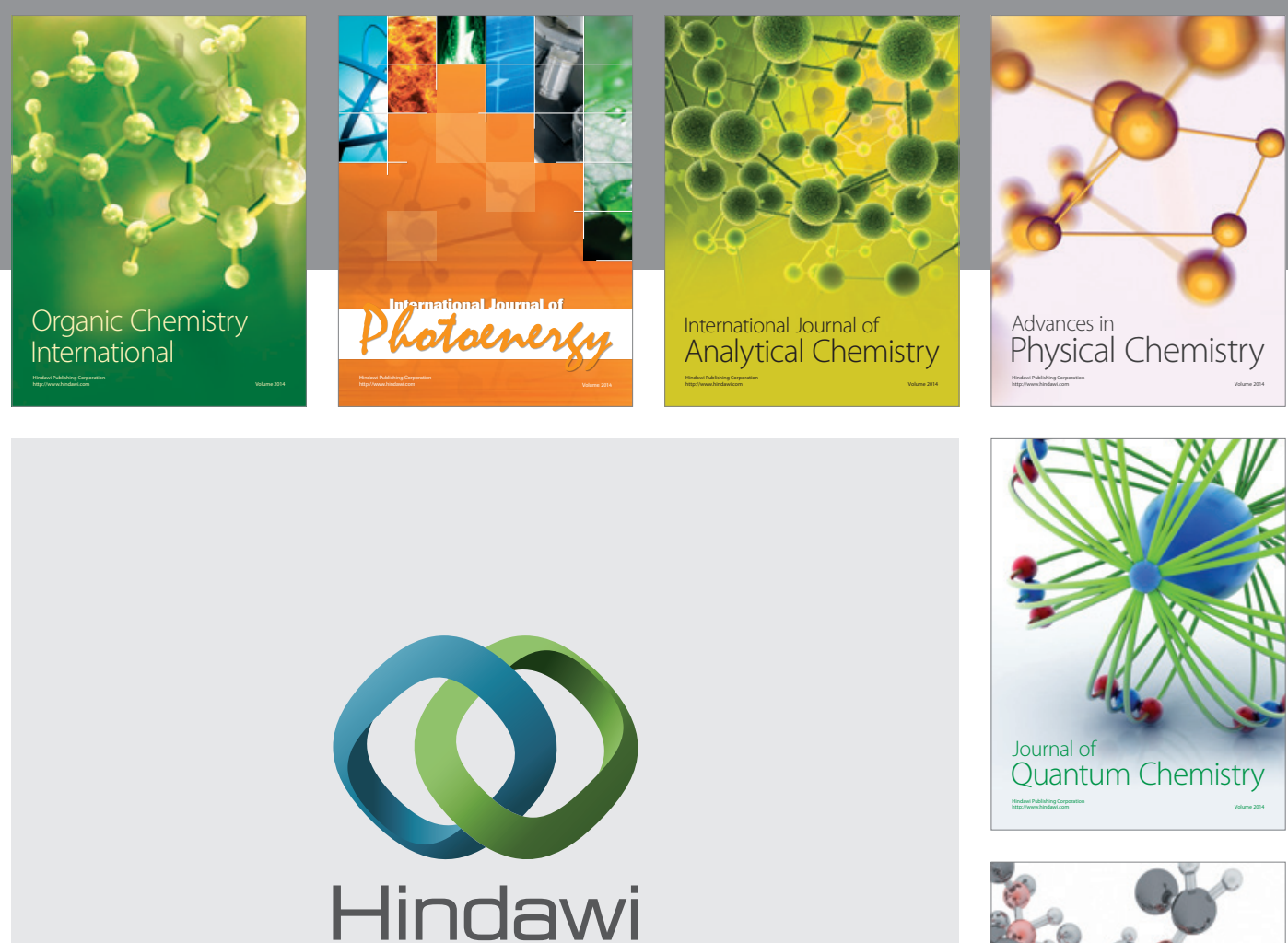

Submit your manuscripts at

http://www.hindawi.com

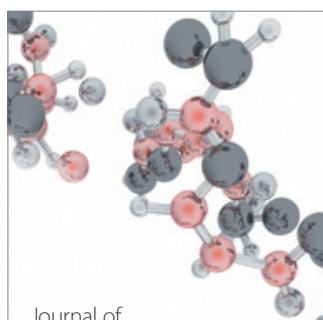

Analytical Methods

in Chemistry

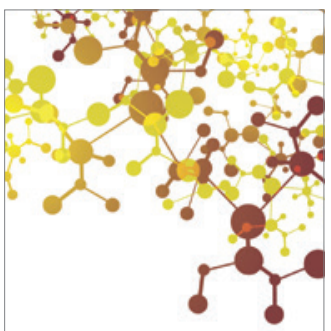

Journal of

Applied Chemistry

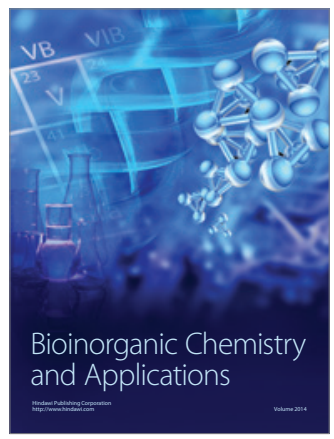

Inorganic Chemistry
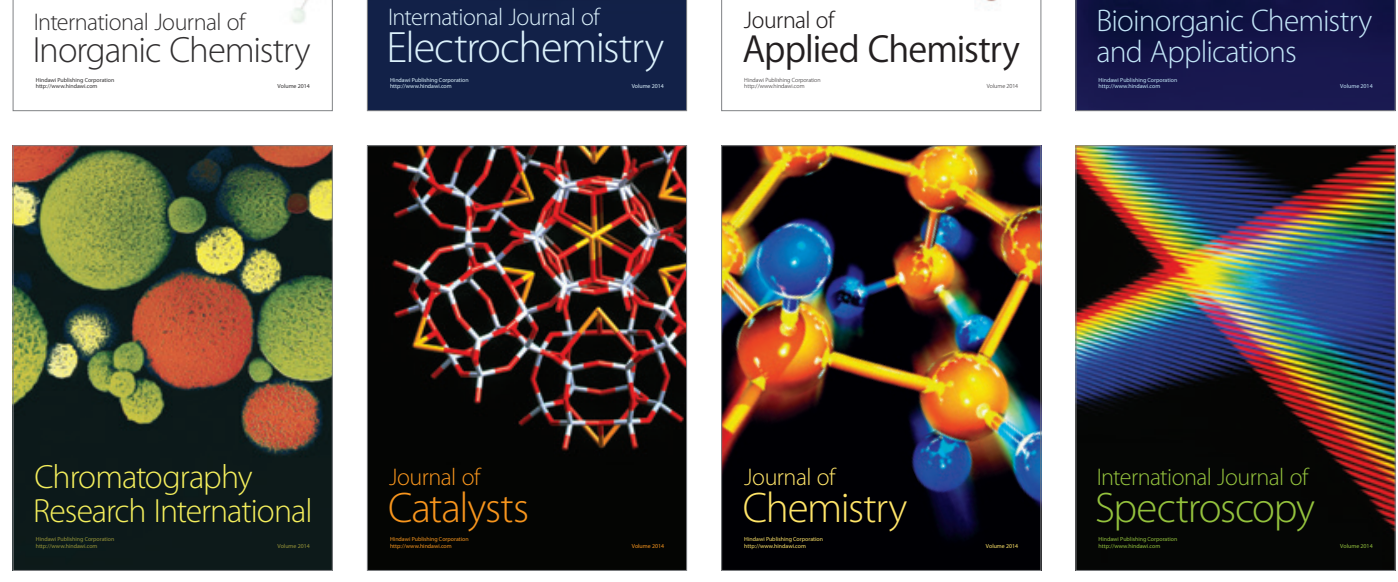